\title{
Keynotes
}

\section{Research troikas: a plan for fostering psychiatric research in a region}

\author{
ANDREw Sims, Professor of Psychiatry, St James's University Hospital, Leeds LS9 7TF
}

Without research psychiatry is brain dead! Perhaps the most significant discriminator between medical practice and the 'alternative therapies' is the responsibility, often honoured, of the medical profession to evaluate and hence vindicate its treatment methods. For the individual practitioner, research helps to maintain the highest standards of involvement in clinical care. In psychiatry many new methods of treatment and innovatory types of treatment service have been introduced over recent years. Their continued and extended use should not be justified by the zeal of their advocates but by demonstration of their efficacy.

A recurrent theme at present is that psychiatrists wish to be involved to a greater extent in research, but for various reasons, feel that they are frustrated from doing so: lack of training, lack of time, lack of resources. Research is, however, the key to future progress in psychiatry. As well as increasing academic interest in our discipline and the possibility of advancing knowledge, completed research and publication is seen to have other, perhaps more tangible, advantages.

Psychiatric trainees increasingly realise that with the high calibre of application for senior registrar, and now also registrar, posts, research publications are likely to help them in being placed on a short-list for an Advisory Appointments Committee (Lewis, 1991). National Health Service consultants see current publication as making a contribution in consolidating their position among their peers in psychiatry and other medical specialties. Academic consultants are increasingly being encouraged by their universities to increase their involvement in research, even at the expense of other parts of their work including administration, clinical work and teaching. Each of these three groups describe great difficulties in carrying out research, but the problems that each encounters are different, and so there appears to be scope for encouraging collaboration.

If these different groups could work together to a greater extent there would be advantages for the
National Health Service in its Regions, Districts, Units and Trusts:

(a) in the training of future consultants

(b) for maintaining the interest and developing skills of current consultants

(c) new knowledge benefits all, including those locally

(d) carrying out local, investigative research for the benefit of the service

(e) publication brings kudos to the service.

Similarly, there are advantages for the university in increasing the manpower for research without additional salaries; collaborative research initiated with the National Health Service may lead to largerscale funded research; publications are also of benefit to the University. Such work would also have advantages for the Specialty of Psychiatry, and its future development.

A troika is "a Russian vehicle with a team of three horses abreast" (Concise Oxford Dictionary, 1990). The three horses have different but equal responsibilities, and smooth progress depends upon all three pulling hard, and together.

\section{The study}

The aim is to set up research 'troikas', involving collaboration in research between a psychiatric trainee, National Health Service consultant, and academic psychiatrist.

\section{What each 'horse' can provide}

The point of this combination of research effort is that the three different elements have quite different strengths, and the resultant power of their combination is much greater than the sum of their individual contributions.

(a) The trainee brings to the project time, the ability to carry out 'leg work', and recent training and factual knowledge in psychiatry and medicine. 
(b) The consultant is responsible for a number of patients and knows local services well. $\mathrm{He} /$ she also has practical, clinical experience and may be able to provide some clerical resources, equipment and accommodation, which are often at a premium in a university department. It may be easier for the consultant to obtain a research grant from the regional health authority or other local funder than others.

(c) The academic psychiatrist brings knowledge of research method and planning, experience in publications, and access to other research specialism within the University. Such a person is also likely to have useful links with other relevant organisations outside the university for carrying out research successfully.

\section{How to set up the scheme}

Such an arrangement depends upon volunteers from each of the three constituencies being matched for skills and abilities, interests and sub-specialty, compatibility and geographical location. If psychiatrists in a region decided to establish research troikas, there would be a need for one person to be identified to organise their setting up and maintenance; this could either be a senior academic or a regional consultant with particular skills and interests in research organisation. There will almost always be a need for small-scale funding for travelling expenses, pilot studies, necessary clerical work, and so on. There is therefore a need in setting up a regional scheme for contact with the National Health Service and regional research and development strategies; the scheme itself will require some funds for its institution, and 'pump priming' will be required to initiate projects. This will be essential to get such a system established before an individual projects are undertaken.

\section{Procedure for each troika}

It is probable that each member of the troika will require training in research methods appropriate to their experience before being effective. Pelosi (1992) considered that only a small number of psychiatric consultants nationally are able to supervise research. There will often be a need, therefore, for further training for the consultant as well as the trainee. The academic may well need to take advantage of courses available within the University.

Once the troika has been identified they should meet and identify individual and collective goals. How will the troika set goals and maintain deadlines? It will be necessary to set a timed programme - and then keep to it! Does someone need to be identified to take the lead? The stages to be considered follow.

(a) Setting up the project. This involves identifying the area of work, detailed planning of method, seeking appropriate funding if necessary, and apportioning work to each member.

(b) Carrying out the work. Obviously it is very important that each 'horse' knows precisely and carries out its individual responsibilities. The work-load must be appropriate to individual resources of time, knowledge and experience. In a simple field study, the trainee may be carrying out most of the data collection; the consultant may have provided the setting for the study to take place and may be providing clinical back-up with treatment if necessary; and the academic will probably be responsible for maintaining the quality of data and its subsequent analysis.

(c) Analysis, writing the report and publication. Again this part of the work should be apportioned appropriately according to the particular skills of each individual and also the time they have available. It is necessary for one person, perhaps the academic, to ensure that progress is being made and that the project goes through the various necessary stages until publication is achieved.

\section{Findings}

'Troikas' may be established as described above. After an appropriate time interval they should be evaluated. Of interest would be the number of volunteers from each of the three constituencies, the number of successful troikas established, and the number of publications that have been produced.

It would also be important to establish the benefit that has arisen from such a structure for the individuals involved, for the Psychiatric Department and University, for the NHS Unit, Trust or Region, and also for the whole discipline of psychiatry. It would also be useful to ascertain at what stage failures in the successful establishment and working of troikas occur.

\section{Concluding remarks}

There are many difficulties in carrying out successful research and publication in psychiatry, and different problems are described by each of the following: psychiatric trainees, National Health Service consultants and academic psychiatrists. There is scope for collaboration between these and a suitable model could be a research 'troika' - where three 
'horses' pull a load that none of them could manage individually. How such research troikas could be set up to carry out their activities is described. It would be very important that such a project was evaluated both quantitatively and in terms of the benefits accruing to each individual and employing authority.

\section{References}

LEWIS, S. (1991) The right stuff? A prospective controlled trial of trainees' research. Psychiatric Bulletin, 15, 478-480.

Pelosi, A. (1992) Research training in psychiatry: "By their fruits shall ye know them". Association of University of Teachers of Psychiatry Bulletin, Spring, 1-4.

\title{
Original articles
}

\section{A new discharge summary}

\author{
Susan Smith, Registrar; and Carol Trotter, Consultant Psychiatrist, Elderly Mental \\ Health Division, St James' Hospital, Portsmouth PO14 8LD
}

A good discharge summary is an important part of in-patient psychiatric care. It should provide a useful prècis of the admission in the hospital notes, and also provide the general practitioner with details needed for the immediate and longer term management of the patient after discharge.

\section{The study}

The quality of summaries and their adequacy to the needs of GPs have been recently examined. The aim of our study was to examine the effect of a newly introduced set format on the time taken to complete the summary after discharge. We also wanted to look at how this approach improved the content of summaries.

The study was carried out within the Elderly Mental Health Division, St James' Hospital, Portsmouth. The hospital serves a total catchment area of 270,000 of which about 56,000 are over 65 years and therefore come under the care of the department should they develop mental health problems.

The new format was introduced in April 1991, and included headings of prognosis and information given to patients and relatives. These were items noted in the recent studies to be poorly covered, but felt to be very important by GPs.

The summary was ideally to be completed at the last consultant ward round, prior to discharge, although this was not always practical.

All patients discharged in the months of May 1990 and May 1991 were looked at. Where discharge summaries were present, they were examined for the delay between discharge and writing, and also the information contained within them.

\section{Findings}

In May 1990, 42 patients were discharged. Of these, there were 29 summaries completed. Of the remaining 13, four patients had died and nine had been brief admissions for arranged shared care.

In May 1991, 45 patients were discharged. For these, 32 summaries were completed. One of the remaining 13 was a brief admission who returned to another area, and 12 were admissions for shared care. No patients studied died during this time so we looked at 29 summaries from May 1990 and May 1991. The percentage of summaries completed in six days or less improved from $48 \%$ to $84 \%$, with a mean of seven days to complete summaries in 1990 